\title{
ACANTHOSIS NIGRICANS: A MARKER PREDICTING METABOLIC SYNDROME AMONG ADOLESCENTS AND ADULTS
}

\begin{tabular}{ll} 
B. Shravya* & Postgraduate Final Year. ${ }^{*}$ Correspondng Author \\
\hline Dr. P. Vidyasagar & Associate Professor, Dept Of DVL. \\
\hline $\begin{array}{l}\text { Dr. Chinnapu } \\
\text { Reddy }\end{array}$ & Associate Professor, Dept Of Biochemistry. \\
\hline
\end{tabular}

ABSTRACT INTRODUCTION: Metabolic syndrome is a cluster of metabolic risk factors which includes central obesity, glucose intolerance, hyperinsulinemia, low HDL cholesterol, high triglycerides and hypertension. Acanthosis nigricans, the principal abnormality in metabolic syndrome (MetS), is an easily identifiable asymptomatic non-specific reaction pattern of skin characterized by thickened, hyperpigmented plaques associated with hyperinsulinemia. AIMS AND OBJECTIVES: To determine the prevalence of metabolic syndrome and AN in adolescent and adults and the association between benign acquired AN and metabolic syndrome. MATERIALS AND METHODS: A sample of 40 patients selected from Dermatology outpatient department who satisfied the selection criteria to evaluate the prevalence of AN and its association with insulin resistance and the clustering of the MetS components. Epidemiological, clinical and anthropometric characteristics (height, weight, waist circumference) were measured and BMI was calculated. We used the National Cholesterol Education Program Adult Treatment Panel III (NCEP ATP III) criteria for the diagnosis of metabolic syndrome. RESULTS: The average age of the study population was 26.8 years, with male to female ratio of $1: 1$. The prevalence of acanthosis nigricans among females is greater than males, which also showed a positive correlation with increase in the age. BMI was higher in patients with metabolic syndrome than the patients without metabolic syndrome.There was a statistically significant correlation of increasing incidence of AN with each component of metabolic syndrome. CONCLUSION: There is an increased prevalence of MetS in the individuals with AN which was statistically highly significant. Hence, early screening of a simple clinical marker like AN is helpful in identification of MetS components.

KEYWORDS : Acanthosis Nigricans, Metabolic Syndrome, Hyperinsulinemia, Hyperlipidemia, Diabetes Mellitus.

\section{INTRODUCTION}

Acanthosis nigricans (AN) is a clinically diagnosed dermatological condition characterized by symmetrical hyperpigmentation, hyperkeratosis, and papillomatosis typically involving the posterior neck, axillae, elbows, and knees. ${ }^{1}$ Benign AN is very common and affects up to $20 \%$ of adults and $7 \%$ of children. ${ }^{2,3}$ It is often associated with obesity, hyperinsulinemia, and insulin resistance. Sinha and Schwartz had classified AN as benign AN, obesity-associated AN, syndromic AN, malignant AN, acral AN, unilateral AN, drug-induced $\overline{A N}$, and mixed $\mathrm{AN} .{ }^{4}$ Occurrence of $\mathrm{AN}$ increases with age and shows no gender difference, whereas some studies reveal a higher prevalence in women with obesity or diabetes.

\section{Metabolic syndrome}

According to the National Cholesterol and Education Program Adult Treatment Panel III (NCEP ATP III) criteria, the presence of three of the following five conditions is needed for diagnosing a patient as having metabolic syndrome: Abdominal obesity, hypertriglyceridemia, low high-density lipoprotein cholesterol (HDL-C) levels, elevated blood pressure, and high fasting glucose levels.

Five parameters of metabolic syndrome:

- Waist circumference $>102 \mathrm{~cm} / 40$ inches for male and $>88$ $\mathrm{cm} / 36$ inches for female;

- $\quad \mathrm{TG}>1.7 \mathrm{mmol} / \mathrm{L}(150 \mathrm{mg} / \mathrm{dL})$.

- HDL-C $<40 \mathrm{mg} / \mathrm{dL}$ for male and $<50 \mathrm{mg} / \mathrm{dL}$ for female;

- Blood pressure (BP) >130/85 mmHg;

- Fasting glucose $>6.1 \mathrm{mmol} / \mathrm{L}(110 \mathrm{mg} / \mathrm{dL})^{5}$

Insulin resistance is the primary metabolic disorder associated with obesity and appears to be the most likely underlying mechanism in metabolic syndrome. The metabolic syndrome (MetS) increases the risk of cardiovascular disease and cardiovascular mortality. ${ }^{5}$ It was first named as "Syndrome X" by Reaven. ${ }^{6}$ Lipoatrophy, AN, skin tags, and psoriasis are common skin markers associated with this syndrome.

\section{Acanthosis nigricans and metabolic syndrome}

There is substantial evidence that patients with AN bear a higher risk for developing the metabolic syndrome (METS). Understanding the connection between AN and MS is critical for clinicians since patients with AN are at risk for all of the components of the MS. Recent data show that about one-third of the urban population in large cities in India have MetS.'

As there is a paucity of data in the Indian population, this study was intended to evaluate the association of benign acquired AN with MetS in a subpopulation of the rural background.

\section{AIMS AND OBJECTIVES}

(1) To determine the prevalence of metabolic syndrome and AN in adolescent and adults and the association between benign acquired AN and MetS [biochemical, metabolic and anthropometric parameters] (2) To observe the fasting and postprandial blood sugar level, lipid profile, blood pressure, and waist circumference (WC) in patients with AN.

\section{MATERIALS AND METHODS}

We recruited a sample of 40 patients selected from regular outpatient department who satisfied the selection criteria to evaluate the prevalence of AN and its association with insulin resistance and the clustering of the MetS components. This cross sectional study has been conducted in the department of Dermatology, Venereology and Leprosy at KAMINENI INSTITUTE OF MEDICAL SCIENCES, Narketpally.

Inclusion criteria included patients with age ranging from 15 40 years diagnosed clinically with acanthosis nigricans after informed written consent from patient or guardian (if minor). The patients not willing for study, pregnant women, and those on medications which can cause drug induced acanthosis nigricans were excluded from the study. 
The study was approved by the KIMS Ethics Committee, Kamineni institute of medical sciences, Narketpally.

\section{Data collection}

All the patients were evaluated for the clinical signs of metabolic syndrome and AN. Patients are considered to have acanthosis nigricans if they had dermatosis characterised by velvety, papillomatous, brownish black, thickened, hyperpigmented plaques, typically of intertriginous surfaces and neck.

A detailed history of all patients based on standard questionnaire has been taken with emphasis on history of darkening of skin, duration, onset, initial site and distribution of acanthosis nigricans. Personal history of diabetes mellitus, hypertension, polycystic ovarian disease and cardiovascular disease has been noted. Weight, height, waist circumference (WC), and systolic and diastolic blood pressure were measured. Family history of darkening of skin, hypothyroidism, hyperthyroidism, diabetes mellitus, hypertension, cardiovascular disease, malignancy has been recorded.

Individuals reporting a history of hypertension, those under medication and elevated blood pressure were defined as having hypertension. Blood samples were obtained from all subjects to test the levels of fasting glucose, insulin, HDL-C, and triglycerides (Tgs). Serum insulin levels have been measured by enzyme immunoassay. Blood glucose levels were measured by glucose oxidase-peroxidase method. The patients underwent 75-gram oral glucose tolerance tests (OGTT). Diagnosis of glucose intolerance was based on the American Diabetes Association's definitions for diabetes mellitus, impaired fasting glucose (IFG) and impaired glucose tolerance (IGT). ${ }^{8}$ Subjects with a fasting plasma glucose $(F P G) \geq 126 \mathrm{mg} / \mathrm{dL}$ and/or a 2-hr plasma glucose $\geq 200 \mathrm{mg} / \mathrm{dL}$ were classified as having diabetes. A 2-hr plasma glucose 140-199 mg/dL indicated the presence of IGT. IFG was defined as a FPG 100-125mg/dL. Normoglycemia was considered to be a FPG $<100 \mathrm{mg} / \mathrm{dL}$ and a 2-hr plasma glucose $<140 \mathrm{mg} / \mathrm{dL}$. Subjects diagnosed with diabetes, IFG, or IGT were defined as having glucose intolerance.

For fasting serum lipid parameters, cholesterol measurement have been performed using cholesterol oxidase-peroxidase method (CHOD-POD). Triglycerides have been measured by Glycerol-3-oxidase peroxidase with N-ethyl S-Sulphopropyl anisidine (GPO-POD with ESPAS). LDL, HDL, VLDLcholesterol have been calculated by direct enzymatic method. Total cholesterol >250mg\%, LDL cholesterol >130mg\%, triglycerides $>150 \mathrm{mg} \%$, VLDL $>40 \mathrm{mg} \%$ is considered raised, whereas HDL $<35 \mathrm{mg} \%$ is considered low. We used the NCEP ATP III criteria for the diagnosis of metabolic syndrome.

\section{Statistical analysis}

Data were analysed using SPSS Software. Results were expressed as mean-standard deviation (SD). Paired t-test has been used for statistical significance for hirsutism whereas student t-test (two tailed, independent) was used for calculating the statistical significance of other parameters.

Significant figures have been considered as

- Suggestive: when Pvalue is $0.05<\mathrm{P}<0.10$

- Moderate: when P value is $0.01<\mathrm{P} \leq 0.05$

- Strong: when $\mathrm{P}$ value is $\mathrm{P} \leq 0.01$

Chi-square test has been used to find the significance of the parameters on categorical scale between two or more groups (used for gender).

\section{RESULTS}

In the current study, we addressed 40 AN Patients comprising of 20 males and 20 females (mean age $26 \pm 8.75$ years; BMI $30.2 \pm 9.24 \mathrm{~kg} / \mathrm{m}^{2}$ ) with the youngest patient being 15 years and the eldest being 40 years old, majority of the patients having lesions on the nape of the neck.

Of the five metabolic syndrome components, AN was correlated with increased WC, high TGs, and low HDL-C levels. We found that $70 \%$ of the subjects met at least three criteria of NCEP ATP III and were diagnosed with metabolic syndrome. The values of triglycerides, HDL, WC in these cases of AN were statistically significant. The values of systolic and diastolic blood pressure (SBP and DBP) and fasting blood sugar were not statistically significant. We observed that $70 \%$ of the patients with metabolic syndrome met three criteria, $17.5 \%$ met four, and $12.5 \%$ met five criteria. The prevalence of components of metabolic syndrome are shown in Table 1.

Table 1: Prevalence of Components of Metabolic Syndrome in Adolescents and Adults according to the NCEP ATP III Criteria

\begin{tabular}{|l|l|}
\hline Criteria & $\begin{array}{l}\text { Percentage of Subjects with } \\
\text { metabolic syndrome } \\
\text { components (n=40) }\end{array}$ \\
\hline Elevated blood pressure (\%) & $12.5(\%)$ \\
\hline Increased WC (\%) & $30(\%)$ \\
\hline Elevated FPG (\%) & $17.5(\%)$ \\
\hline Elevated TG (\%) & $22.5(\%)$ \\
\hline Low HDL-C (\%) & $17.5(\%)$ \\
\hline
\end{tabular}

NCEP ATP III, National Cholesterol Education Program Adult Treatment Panel III; WC-waist circumference; FPG-fasting plasma glucose; TGs-triglycerides; HDL C- high density lipoprotein cholesterol.

Patients with metabolic syndrome were older $(26.2 \pm 6.7$ vs $23.5 \pm 3.2$ years, $\mathrm{P}=0.003$ ) and had more increased BMI (33.4 \pm 6.8 and $26.8 \pm 7.5 \mathrm{~kg} / \mathrm{m}^{2}, \mathrm{P}=0.0001$ ) compared to patients without metabolic syndrome. Abdominal obesity was the most frequent $(72 \%)$ component of metabolic syndrome among the subjects. Additionally, HOMA-IR levels were higher in the metabolic syndrome-positive group than in the metabolic syndrome-negative group $(8.4 \pm 2.1 \%$ vs $3.2 \pm 1.5 \%$, $\mathrm{P}=0.0001$ ). BMI, WC, fasting insulin, HOMA-IR, and TGs levels were significantly higher and HDL-C levels were significantly lower in women with AN compared to men. We observed a significant correlation between AN and metabolic syndrome. Additionally, a significant positive correlation was found between AN and BMI, fasting insulin, and HOMA-IR, where the majority were insulin resistant (55\%).

Table 2: Comparison of the severity of acanthosis nigricans with metabolic syndrome

\begin{tabular}{|l|l|l|l|}
\hline \multirow{2}{*}{ Severity of AN } & Metabolic Syndrome & \multirow{2}{*}{ Total } \\
\cline { 2 - 3 } & Yes & No & \\
\hline Grade I & $4(44.4 \%)$ & $5(55.5 \%)$ & 9 \\
\hline Grade II & $6(60 \%)$ & $4(40 \%)$ & 10 \\
\hline Grade III & $8(88.8 \%)$ & $1(11.1 \%)$ & 9 \\
\hline Grade IV & $10(83.3 \%)$ & $2(16.6 \%)$ & 12 \\
\hline Total & 28 & 12 & 40 \\
\hline
\end{tabular}

Relation of severity of acanthosis nigricans with metabolic syndrome

- Grade 1-44.4\% had MS, whereas 55.5\% did not have MS

- Grade 2-60\% had MS, whereas $40 \%$ did not have MS

- Grade 3-88.8\% had MS, whereas $11.1 \%$ did not have MS

- Grade $4-83.3 \%$ had MS, whereas $16.6 \%$ did not have MS (Pvalue $=0.000)$.

On comparing the severity of AN with components of MS and BMI, we found that AN neck severity grading has statistically significant correlation with all the components of MS and BMI. 
Table 3: Descriptive statistics of various laboratory investigations

\begin{tabular}{|c|c|c|c|c|c|}
\hline \multirow[t]{2}{*}{$\begin{array}{l}\text { Lab } \\
\text { investigations }\end{array}$} & \multirow{2}{*}{\begin{tabular}{|l|} 
Number of \\
patients with \\
percentage \\
$(\mathrm{n}=40)$
\end{tabular}} & \multicolumn{4}{|c|}{$\begin{array}{l}\text { Descriptive statistics of lab } \\
\text { investigations }\end{array}$} \\
\hline & & $\begin{array}{l}\text { Mini- } \\
\text { mum }\end{array}$ & $\begin{array}{l}\text { Maxi- } \\
\text { mum }\end{array}$ & Mean & $\begin{array}{l}\text { Standard } \\
\text { deviation }\end{array}$ \\
\hline \multicolumn{6}{|l|}{ FBS (mg/dl) } \\
\hline$<110$ & $33(82.5 \%)$ & \multirow[t]{2}{*}{65} & \multirow[t]{2}{*}{135} & \multirow[t]{2}{*}{86.54} & \multirow[t]{2}{*}{13.56} \\
\hline$>110$ & $7(17.5 \%)$ & & & & \\
\hline \multicolumn{6}{|c|}{ Blood pressure (mm Hg) } \\
\hline$<130 / 85$ & $35(87.5 \%)$ & \multirow[t]{2}{*}{$90 / 50$} & \multirow{2}{*}{$\begin{array}{l}160 / \\
100\end{array}$} & \multirow{2}{*}{$\begin{array}{l}118 / \\
80\end{array}$} & \\
\hline$>130 / 85$ & $5(12.5 \%)$ & & & & \\
\hline \multicolumn{6}{|c|}{ Triglycerides (mg/dl) } \\
\hline$<150$ & $31(87.5 \%)$ & \multirow[t]{2}{*}{61} & \multirow[t]{2}{*}{393} & \multirow{2}{*}{$\begin{array}{l}138 . \\
56\end{array}$} & \multirow{2}{*}{68.04} \\
\hline$>150$ & $9(22.5 \%)$ & & & & \\
\hline \multicolumn{6}{|c|}{ HDL cholesterol (mg/ dl) } \\
\hline$<40$ : males & $3(42.85 \%)$ & 30 & 99 & 43.81 & 10.57 \\
\hline$<50$ : females & $4(57.14 \%)$ & 28 & 104 & 41.83 & 10.98 \\
\hline \multicolumn{6}{|c|}{ Waist circumference (inches) } \\
\hline$>40:$ males & $4(33.3 \%)$ & 24 & 44 & 36 & 9.3 \\
\hline$>36:$ females & $8(66.6 \%)$ & 26 & 46 & 38 & 8.9 \\
\hline
\end{tabular}

The above data shows:

- Thirty three (82.5\%) had FBS $<110 \mathrm{mg} / \mathrm{dl}$, seven (17.5\%) had FBS $>110 \mathrm{mg} / \mathrm{dl}$.

- Thirty five (87.5\%) had blood pressure < 130/85, five (12.5\%) had blood pressure $>130 / 85 \mathrm{~mm} \mathrm{Hg}$.

- Thirty one (87.5\%) had triglycerides $<150 \mathrm{mg} / \mathrm{dl}$, nine (22.5\%) had triglycerides $>150 \mathrm{mg} / \mathrm{dl}$.

- Three male (42.85\%) had HDL $<40 \mathrm{mg} / \mathrm{dl}$ and four female (57.14\%) had HDL $<50 \mathrm{mg} / \mathrm{dl}$.

- Waist circumference was $>40$ inches in four male (33.3\%) and waist circumference was $>36$ inches in eight females (66.6\%).

\section{DISCUSSION}

The most common associations with benign AN are obesity and insulin resistance. Obesity is a well-known risk factor for the metabolic syndrome. ${ }^{9,10}$ In the National Health and Nutrition Examination Survey III (NHANES III), the metabolic syndrome was present in $5 \%$ of those at normal weight and $60 \%$ of those who were obese. ${ }^{9}$ Similarly, we found a positive correlation between BMI and AN in our study. Although all the patients appear normal, BMI was higher in patients with metabolic syndrome than the patients without metabolic syndrome. Increasing age is another risk factor for metabolic syndrome. In 2006, a large population study showed that more than one-third (35.08\%) of the subjects were obese and $27.3 \%$ of the individuals had metabolic syndrome in Turkey. ${ }^{11}$

In NHANES III, the prevalence of metabolic syndrome rose with age and reached peak levels in the sixth decade for men and the seventh decade for women. In our study, we showed that the patients with metabolic syndrome were older than the patients without metabolic syndrome. Insulin resistance plays a major role as the underlying cause for the development and potentiation of the metabolic syndrome, and we found higher HOMA-IR values in patients with metabolic syndrome compared to the patients without metabolic syndrome. AN is a reliable cutaneous marker of hyperinsulinemia and insulin resistance. $^{12}$

In this study, 40 cases of acanthosis nigricans were studied to correlate metabolic syndrome with acanthosis nigricans. Majority of the patients were between $15-40$ years with mean age $26.8 \pm 10.69$ which was similar to the study conducted by Huang et al. ${ }^{13}$ where the mean age groupwas $30.25 \pm 9.28$.

We studied 20 females(50\%) and 20 males(50\%) (male: female $=1: 1$ ) which is comparable to studies carried out by Shah NG 2019(females -62\% and males -38\%), Nithun TM et al 2019(females-75\% and males- 25\%) ${ }^{14}$, Varthakavi et al 2002(females-77.8\% and males-22.2\%). ${ }^{15}$

In the present study, we found a positive correlation between AN and TG levels and a negative correlation between AN and HDL-C levels. The value of triglycerides in cases was statistically significant (57\%). Similar results were seen in studies conducted by Sharquie et al., ${ }^{16}$ Vieira et al., ${ }^{17}$ and Dassanayake et al. ${ }^{18}$ The number of cases of AN with deranged value of HDL and WC as $76 \%$ and $74 \%$, respectively,was higher and statistically highly significant which was similar to the results seen in studies conducted by Vieira et al., ${ }^{17}$ Dassanayake et al., ${ }^{18}$ and Koh et al..$^{19}$

In our study, the value of SBP was not statistically significant when cases were compared with that of controls. A similar result was seen in a study conducted by Vieira et al. ${ }^{17}$ and Kong et $a .^{20}$ However, we did not observe a relationship between blood pressure and AN.

In a 2007 cohort of middle-aged adults, AN was present in 296 of 1025 subjects with metabolic syndrome (29\%) and 217 of 1924 subjects without the syndrome (11\%). In another study, $49 \%$ of the children who had AN were diagnosed with metabolic syndrome. ${ }^{21}$ In the current study, the ratios are higher for the presence of AN in metabolic syndrome-positive groups than-negative groups. We showed that AN was significantly associated with metabolic syndrome, especially with the components of WC, high TGs, and low HDL-C levels. These findings suggest that AN has clinical utility in identifying patients at increased risk of metabolic syndrome.

\section{CONCLUSION}

We observed a correlation between AN and abdominal obesity, insulin resistance, and metabolic syndrome. The NCEP ATP III criteria include WC as a measure of abdominal obesity, which is a useful marker of insulin resistance. There is an increased prevalence of MetS in the individuals with AN (57\%) which was statistically highly significant $(\mathrm{P}=0.00013, \mathrm{P}$ $<0.01)$. Our study suggests that like WC, early screening of AN, a simple and useful clinical marker in physical examination is helpful in identifying patients who are susceptible to the metabolic syndrome.

Correction of the contributing factors of MS like obesity, hypertension, and dyslipidemia will assist in the clinical improvement of AN. Clinicians should assess patients with AN for related metabolic and biochemical parameters to advise regarding lifestyle and behavioural modifications at an early stage to avoid the serious consequences of MS like future cardiovascular complications. This study focus the importance of evaluating associated risk factors of MetS in patients with AN.

\section{Conflict of interest: none}

\section{REFERENCES}

1. Burke JP, Hale DE, Hazuda HP, Stern MP. A quantitative scale of acanthosis nigricans. Diabetes Care 1999;22:1655-9.

2. Brickman WJ, Binns HJ, Jovanovic BD, Kolesky S, Mancini AJ, Metzger BE Acanthosis nigricans: $\mathrm{A}$ common finding in overweight youth. Pediatr Dermatol 2007;24:601-6.

3. Otto DE, Wang X, Garza V, Fuentes LA, Rodriguez MC, Sullivan P. Increasing body mass index, blood pressure, and acanthosis nigricans abnormalities in school-age children. J SchNurs 2013:29:442:51

4. Schwartz RA. Acanthosis nigricans. J Am Acad Dermatol 1994;31:1-9.

5. Balaji C, Vindhya M, Gurukul S. Significance of acanthosis nigricans as marker for metabolic syndrome. World J Med Sci 2014;10:295-8.

6. Reaven GM. Role of insulin resistance in human disease (syndrome X): An expanded definition. Annu Rev Med 1993;44:121-31.

7. Ramachandran A, Snehalatha C, Satyavani K, Sivasankari S, Vijay V. Metabolic syndrome in urban Asian Indian adults - A population study using modified ATP III criteria. Diabetes Res Clin Pract 2003:60:199-204.

8. American Diabetes Association. Diagnosis and classification of diabetes mellitus. Diabetes Care 2012;35(Suppl 1): S64-S71.

9. Park YW, Zhu S, Palaniappan L, et al. The metabolic syndrome: Prevalence and associated risk factor findings in the US population from the Third National Health and Nutrition Examination Survey, 1988-1994. Arch Intern Med 2003;163:427-436. 
10. Wilson PW, Kannel WB, Silbershatz $\mathrm{H}$, et al. Clustering of metabolic factors and coronary heart disease. Arch Intern Med 1999; 159:1104-1109.

11. Sanisoglu SY, Oktenli C, Hasimi A, et al. Prevalence of metabolic syndromerelated disorders in a large adult pop- ulation in Turkey. BMC Public Health 2006;6:92

12. Hud JA Jr, Cohen JB, Wagner JM, et al. Prevalence and significance of acanthosis nigricans in an adult obese pop- ulation. Arch Dermatol 1992;128:941-944.

13. Huang $Y$, Yang J, Li Y, Chen J, Song $K$, Wang X, et al. FGF21 is associated with acanthosis nigricans in obese patients. Int JEndocrinol 2016;2016:1658062.

14. Nithun TM, Ranugha PS, Betkerur JB, Shastry V. Association of acanthosis nigricans and insulin resistance in Indian children and youth - A HOMA2-IR based cross-sectional study. Indian Dermatol Online J 2019:10:272-8.

15. Varthakavi PK, Waingankar A, Patel KL, Wadhwa SL, Khopkar U, Sengupta $\mathrm{RA}$,et al. Acanthosis nigricans: a dermatologic marker of metabolic disease. Indian J Dermatol VenereolLeprol 2002;68:67-72.

16. Sharquie K, Noaimi A, Mahmood H, Al-Ogaily S. Clinical and biochemical evaluation of facial acanthosis nigricans. J Cosmet Dermatol Sci Appl 2015;5:231-7.

17. Vieira CE, Mariz LS, Medeiros CC, Enders BC, Coura AS.Nursing care in childcare services: Acantose nigricans as a marker for metabolic risk. Rev Lat Am Enfermagem 2013;21:1220*7.

18. Dassanayake AS, Kasturiratne A, Niriella MA, Kalubovila U, Rajindrajith S, de Silva AP, et al. Prevalence of acanthosis nigricans in an urban population in Sri Lanka and its utility to detect metabolic syndrome. BMC Res Notes 2011;4:25.

19. Koh YK, Lee JH, Kim EY, Moon KR. Acanthosis nigricans as a clinical predictor of insulin resistancein obese children. Pediatr Gastroenterol Hepatol Nutr 2016:19:251-8.

20. Kong AS, Williams RL, Smith M, Sussman AL, Skipper B, Hsi AC, et al. Acanthosis nigricans and diabetes risk factors: Prevalence in young persons seen in Southwestern US primary care practices. Ann Fam Med 2007:5:202:8.

21. Ice CL, Murphy E, Minor VE, et al. Metabolic syndrome in fifth grade children with acanthosis nigricans: Results from the CARDIAC project. World J Pediatr $2009 ; 5: 23-30$. 